\title{
Solar-Driven Water Oxidation and Decoupled Hydrogen Production Mediated by an Electron-Coupled-Proton Buffer
}

\author{
Leanne G. Bloor, ${ }^{\dagger}$ Renata Solarska, ${ }^{\ddagger}{ }^{\S}$ Krzysztof Bienkowski, ${ }^{\S}$ Pawel J. Kulesza, ${ }^{\ddagger}$ Jan Augustynski, ${ }^{\S}$ \\ Mark D. Symes, ${ }^{* \dagger}$ and Leroy Cronin*, ${ }^{\dagger}$ \\ ${ }^{\dagger}$ WestCHEM School of Chemistry, University of Glasgow, University Avenue, Glasgow G12 8QQ United Kingdom \\ ${ }^{\ddagger}$ Faculty of Chemistry, University of Warsaw, Pasteura 1, 02-093 Warsaw, Poland \\ ${ }^{\S}$ Center of New Technologies, University of Warsaw, S. Banacha 2c, 02-097 Warsaw, Poland
}

\section{Supporting Information}

ABSTRACT: Solar-to-hydrogen photoelectrochemical cells (PECs) have been proposed as a means of converting sunlight into $\mathrm{H}_{2}$ fuel. However, in traditional PECs, the oxygen evolution reaction and the hydrogen evolution reaction are coupled, and so the rate of both of these is limited by the photocurrents that can be generated from the solar flux. This in turn leads to slow rates of gas evolution that favor crossover of $\mathrm{H}_{2}$ into the $\mathrm{O}_{2}$ stream and vice versa, even through ostensibly impermeable membranes such as Nafion. Herein, we show that the use of the electron-coupled-proton buffer (ECPB) $\mathrm{H}_{3} \mathrm{PMo}_{12} \mathrm{O}_{40}$ allows solar-driven $\mathrm{O}_{2}$ evolution from water to proceed at rates of over $1 \mathrm{~mA} \mathrm{~cm}{ }^{-2}$ on $\mathrm{WO}_{3}$ photoanodes without the need for any additional electrochemical bias. $\mathrm{No}_{2}$ is produced in the PEC, and instead $\mathrm{H}_{3} \mathrm{PMo}_{12} \mathrm{O}_{40}$ is reduced to $\mathrm{H}_{5} \mathrm{PMo}_{12} \mathrm{O}_{40}$. If the reduced $\mathrm{ECPB}$ is subjected to a separate electrochemical reoxidation, then $\mathrm{H}_{2}$ is produced with full overall Faradaic efficiency.

$\mathrm{T}^{\mathrm{r}}$ he need to develop carbon-neutral energy sources is rapidly becoming an environmental and economic imperative. ${ }^{1}$ Solar power is an especially attractive option for this purpose, as it is both abundant and widely distributed geographically. $^{2}$ Solar irradiation at the earth's surface is inherently intermittent, due to both the weather and the diurnal cycle. This means that if solar power is to be effective as a multi-terawatt power source, then ways to store this energy to use at times when the sun is not shining must be found. ${ }^{3}$

The photoassisted electrolysis of water has been studied by numerous groups as a method by which solar energy could be stored as a fuel $\left(\mathrm{H}_{2}\right){ }^{4}$ However, there remain several challenges to overcome before viable and cost-effective solar-to-hydrogen photoelectrochemical cells can be realized. First, solar power is diffuse, so that low current densities $\left(\sim 10 \mathrm{~mA} \mathrm{~cm}{ }^{-2}\right.$ has been taken as a benchmark for a $10 \%$ efficient solar-to-fuels device under 1 Sun illumination) $)^{5}$ are standard, and even then these current densities are highly variable. Low current densities equate to slow gas production rates, and this can lead to extensive mixing of product gases, both in devices without a headspace separator ${ }^{6 a}$ and even in electrolyzers where "gasimpermeable" membranes such as Nafion are employed. ${ }^{\text {bb-d }}$ At one extreme, this has the potential to produce explosive $\mathrm{H}_{2} / \mathrm{O}_{2}$ gas mixtures. In the less extreme case, where product gas crossover is slower, hydrogen permeating to the anode side of the cell is preferentially oxidized to protons and electrons, while oxygen on the cathode side is preferentially reduced to water. While these reactions prevent the buildup of dangerous headspace compositions, they consume energy and have a detrimental effect on overall solar-to-collected-hydrogen efficiencies. ${ }^{6}$ Gas crossover can be mitigated by using thicker membranes, but this in turn reduces efficiency by introducing greater ohmic resistance in the cell. ${ }^{6 a, c}$

A second challenge in the realization of a practical solar-tohydrogen cell is how the hydrogen itself is harvested. Assuming a current density of $10 \mathrm{~mA} \mathrm{~cm}{ }^{-2}$ for hydrogen production ${ }^{5}$ and a target of producing $500 \mathrm{~g}$ of $\mathrm{H}_{2}$ gas over the course of $8 \mathrm{~h}$ irradiation at 1 Sun, then an array of area $\sim 17 \mathrm{~m}^{2}$ is required (see Section SI-5 in the Supporting Information (SI) for calculation). This is possible in principle (see arguments advanced in ref $3 \mathrm{~b}$ and a functioning PEC system described in ref $4 \mathrm{n}$ ), but collecting $\mathrm{H}_{2}$ from such a high surface area array may be inefficient. Production of hydrogen at a point source would make effective use of any $\mathrm{H}_{2}$ evolution catalyst and would also facilitate pressurization for storage.

We previously reported the concept of the electron-coupledproton buffer (ECPB), whereby the water oxidation and proton reduction half-reactions of water splitting can be completely decoupled in both space and time, Figure $1{ }^{8}$ Taking the example of phosphomolybdate $\left(\left[\mathrm{PMo}_{12} \mathrm{O}_{40}\right]^{3-}\right)$ as the ECPB, this decoupling can be described by the half-reactions:

$$
\begin{aligned}
& {\left[\mathrm{PMo}_{12} \mathrm{O}_{40}\right]^{3-}+2 \mathrm{e}^{-} \rightarrow\left[\mathrm{PMo}_{12} \mathrm{O}_{40}\right]^{5-}} \\
& \mathrm{H}_{2} \mathrm{O} \rightarrow 2 \mathrm{H}^{+}+1 / 2 \mathrm{O}_{2}+2 \mathrm{e}^{-} \\
& {\left[\mathrm{PMo}_{12} \mathrm{O}_{40}\right]^{5-}+2 \mathrm{H}^{+} \rightarrow\left[\mathrm{PMo}_{12} \mathrm{O}_{40}\right]^{3-}+\mathrm{H}_{2}}
\end{aligned}
$$

In our original work, ${ }^{8 \mathrm{a}}$ both of the necessary energy inputs for eqs $1 \mathrm{a} / \mathrm{lb}$ and 2 were provided purely electrochemically. However, we hypothesized that such a system would be amenable to a combined photoelectrochemical cycle, whereby eqs $1 \mathrm{a}$ and $1 \mathrm{~b}$ would be driven in a PEC without a bias voltage and eq 2 would be driven electrochemically (with a bias

Received: March 28, 2016

Published: May 9, 2016 


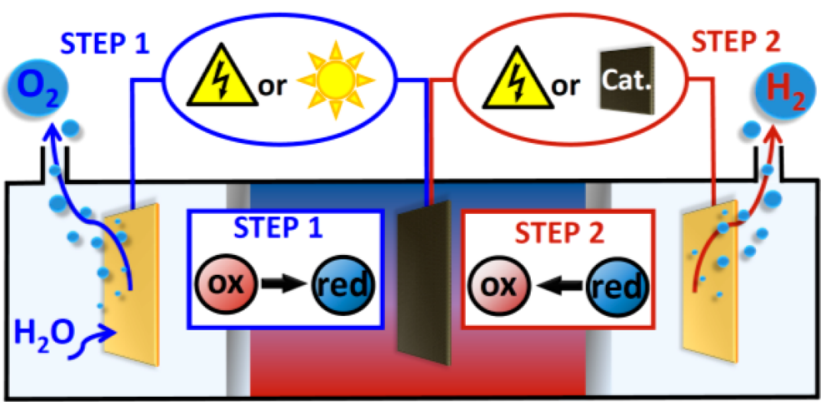

Figure 1. Use of ECPBs allows the electrolysis of water to be split into two steps both spatially and temporally. Step 1 (blue lines) is the oxidation of water concomitant with reduction of the ECPB, and step 2 (red lines) is reoxidation of the ECPB with concomitant hydrogen evolution. Previously, both steps have been driven electrochemical$1 y,{ }^{8 a, b}$ and an electrochemical step 1 followed by a catalytic release of $\mathrm{H}_{2}$ in step 2 has been demonstrated. ${ }^{8 c}$ Herein, we show that step 1 can be performed in a PEC, with an electrochemical step 2 .

voltage). Herein, we demonstrate the feasibility of such a system by using a $\mathrm{WO}_{3}$ photoanode in a PEC to drive the simultaneous oxidation of water to $\mathrm{O}_{2}$ and reduction of $\left[\mathrm{PMo}_{12} \mathrm{O}_{40}\right]^{3-}$ to $\left[\mathrm{PMo}_{12} \mathrm{O}_{40}\right]^{5-}$ without the need for any additional electrical bias. Current densities of over $1 \mathrm{~mA} \mathrm{~cm} \mathrm{~cm}^{-2}$ were achieved under simulated solar irradiation with high Faradaic efficiency for oxygen production, but without any detectable hydrogen production during irradiation (and hence no danger of the product gases mixing). The reduced phosphomolybdate could subsequently be reoxidized electrochemically to regenerate $\left[\mathrm{PMo}_{12} \mathrm{O}_{40}\right]^{3-}$ and produce hydrogen with full Faradaic efficiency.

A general schematic of the photoelectrochemical cell for $\mathrm{O}_{2}$ evolution and reduction of the ECPB is given in Figure 2. Tungsten trioxide was chosen as the photoanode because it is stable under the $\mathrm{pH}$ conditions used in this work $(\mathrm{pH} \mathrm{0.1)}$ and because its band gap straddles both water oxidation onset (ca. $+1.2 \mathrm{~V}$ vs $\mathrm{NHE})$ and the reduction potential of $\left[\mathrm{PMo}_{12} \mathrm{O}_{40}\right]^{3-}$

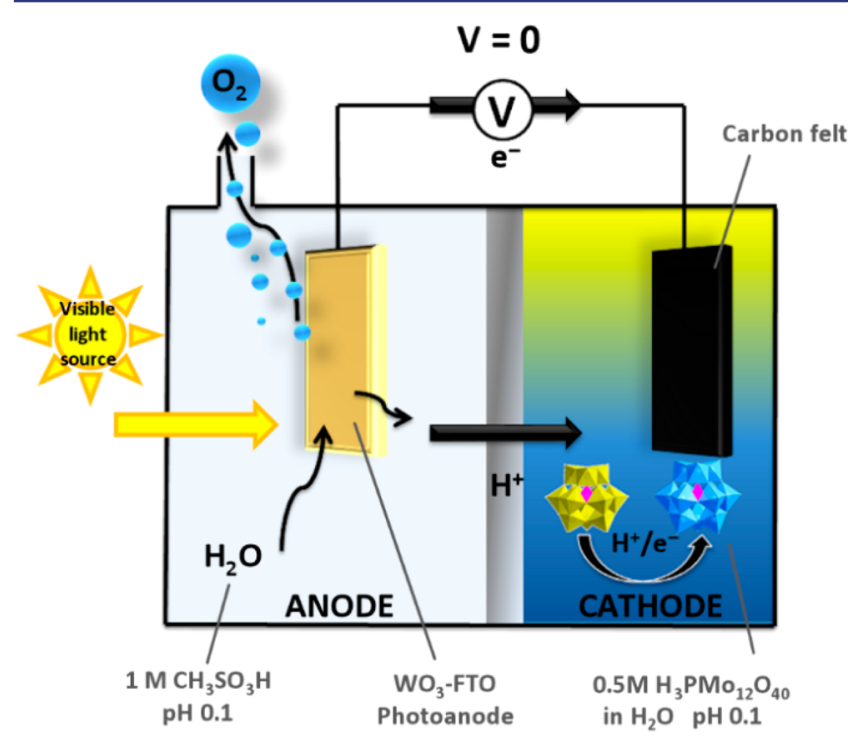

Figure 2. General schematic of the photoelectrochemical cell configuration used to drive water oxidation and concomitant reduction of the ECPB at zero bias. FTO = fluorine-doped tin oxide on glass. The reduction of the ECPB at the cathode is shown as being coupled to protonation as suggested by our previous results (see ref $8 \mathrm{a}$ ). $(\text { ca. }+0.6 \mathrm{~V} \text { vs } \mathrm{NHE})^{8 \mathrm{a}}$ at this $\mathrm{pH} .^{9}$ An airtight cell was thus constructed according to Figure 2, using a $1 \mathrm{~cm}^{2} \mathrm{WO}_{3}$ photoanode (prepared on an FTO substrate by a literature procedure $)^{10}$ in contact with $1 \mathrm{M}$ methanesulfonic acid $(\mathrm{pH}$ 0.1 ) in one compartment and phosphomolybdic acid $\left(\mathrm{H}_{3} \mathrm{PMo}_{12} \mathrm{O}_{40}, 0.5 \mathrm{M}\right.$ in water $)$ in the other compartment in contact with a large area carbon felt electrode. The two chambers were separated by a Nafion membrane, and an electrical connection was established between the photoanode and carbon felt cathode through a potentiostat. The reference and counter electrode leads of this potentiostat were both connected to the cathode to give a floating reference (or twoelectrode) configuration, across which fixed bias voltages could be applied in a controlled fashion (see SI for a full description of the experimental setup). It is important to note that although the ECPB is highly colored, it is retained in the cathode compartment by the membrane such that the photoanode is immersed in a transparent solution containing $1 \mathrm{M}$ methanesulfonic acid only. Hence there is no attenuation of the irradiation reaching the photoanode by the ECPB.

Figure 3 (top) shows a chopped-light experiment in which the applied bias voltage between the photoanode and cathode
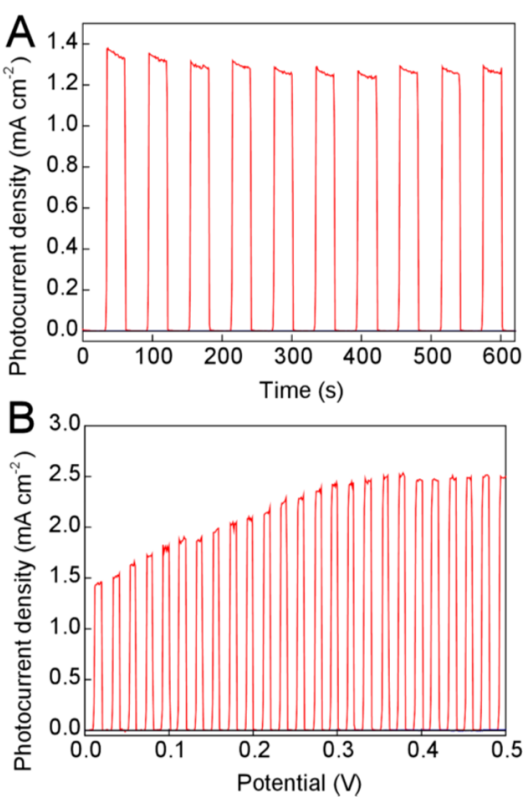

Figure 3. (A) Chopped light experiment in a two-electrode configuration at $0 \mathrm{~V}$ bias, according to the cell setup in Figure 2 (red line). Black line: with $\mathrm{H}_{3} \mathrm{PMo}_{12} \mathrm{O}_{40}$ but using only FTO as the anode. Blue line: with a $\mathrm{WO}_{3}-\mathrm{FTO}$ anode, but using no ECPB. (B) Chopped light experiment in a two-electrode configuration, as above, but with the bias potential varied from 0 to $0.5 \mathrm{~V}$ at a rate of $1 \mathrm{mV} / \mathrm{s}$. Expansions of the low current areas of both these graphs (so that the blue and black traces can be seen more clearly) are given in Figures S2 and $\mathrm{S} 3$.

was fixed at $0 \mathrm{~V}$ (i.e., no external bias), and the photoanode was irradiated periodically with simulated solar light (AM 1.5) at 1 Sun intensity. These results indicated that current densities of well over $1 \mathrm{~mA} \mathrm{~cm}^{-2}$ could be obtained at $0 \mathrm{~V}$ bias in this system under illumination, with the current density falling to zero when the light was turned off (Figure 3a, red line). These results were conducted without any compensation for resistance, which was found to be around $14 \Omega$. Control experiments with an identical setup but using a bare FTO 
electrode without $\mathrm{WO}_{3}$ (Figure 3a, black line) or with an FTO$\mathrm{WO}_{3}$ electrode but with only $1 \mathrm{M}$ methanesulfonic in the cathode compartment (blue line) indicated that both the $\mathrm{WO}_{3}$ photoanode and the ECPB were essential for observing photocurrent under these conditions.

Figure 3 (bottom) shows a chopped light experiment obtained under the same conditions as the red trace in Figure $3 \mathrm{a}$, but this time with the bias voltage being swept from 0 to 0.5 $\mathrm{V}$ at a rate of $1 \mathrm{mV} / \mathrm{s}$ (a sweep over a wider range of potentials is shown in Figures S4 and S5). Hence if modest bias voltages are applied, current densities approaching $2.5 \mathrm{~mA} \mathrm{~cm}^{-2}$ can be obtained. These current densities compare favorably with photocurrents obtained in three-electrode configurations with $\mathrm{WO}_{3}$ photoanodes at low $\mathrm{pH}$, for which maximum current densities under high anodic bias normally plateau at $\sim 1 \mathrm{~mA}$ $\mathrm{cm}^{-2} \cdot 10,11$

During the chopped light experiments described above, bubbling was observed at the anode, while the cathode compartment turned from yellow (characteristic of $\left[\mathrm{PMo}_{12} \mathrm{O}_{40}\right]^{3-}$ ) to blue (indicating reduction to $\left.\left[\mathrm{PMo}_{12} \mathrm{O}_{40}\right]^{5-}\right)$. In order to determine the nature of any gases produced in either compartment, irradiation at 1 Sun and AM 1.5 was conducted at $0 \mathrm{~V}$ bias, while the headspaces of the anode and cathode chambers were investigated by gas chromatography and fluorescence probe spectroscopy (see SI for details). Gas chromatography indicated that oxygen gas was present in the anode headspace, but no hydrogen gas could be detected in either compartment headspace, suggesting that complete decoupling of the water oxidation and proton reduction reactions had occurred in this step. Quantification of the amount of oxygen evolved was possible using an $\mathrm{O}_{2}$ fluorescence-quench probe, and comparison with the total charge passed during irradiation indicated that the Faradaic efficiency for oxygen production by photolytic water splitting was $84 \%( \pm 6 \%)$, see Figure 4 .

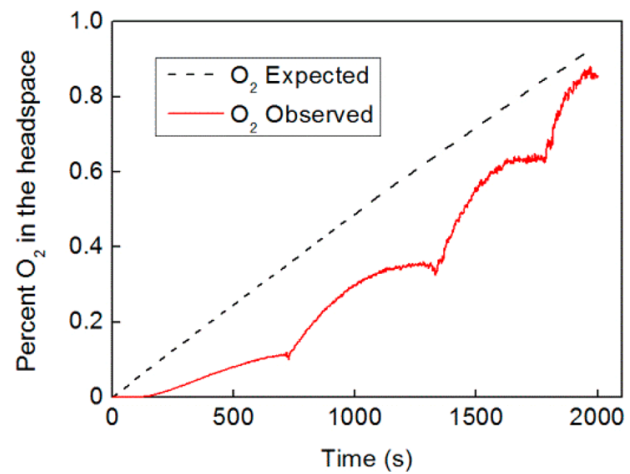

Figure 4. Comparison of the amount of $\mathrm{O}_{2}$ expected in the cell headspace on the basis of the charge passed (black dashed line) and $\mathrm{O}_{2}$ detected in the cell headspace by fluorescence-quench measurements (red line). Bubbles collected on the anode and were periodically dislodged by shaking, accounting for the increments observed in the measured $\mathrm{O}_{2}$ signal.

These results suggest that solar-driven water oxidation can be coupled to reduction of $\left[\mathrm{PMo}_{12} \mathrm{O}_{40}\right]^{3-}$ to give a reduced ECPB without simultaneous hydrogen evolution, such that gas mixing in a working device could be kept to a minimum (even at current densities under irradiation on the order of only $1 \mathrm{~mA}$ $\mathrm{cm}^{-2}$ ).
Our previous work ${ }^{8 \mathrm{a}}$ demonstrated that the reduced form of the ECPB $\left(\left[\mathrm{PMo}_{12} \mathrm{O}_{40}\right]^{5-}\right)$ is stable with respect to reoxidation in air on the time scale of hours-to-days and gives clean reconversion to $\left[\mathrm{PMo}_{12} \mathrm{O}_{40}\right]^{3-}$ with concomitant $\mathrm{H}_{2}$ evolution (at $100 \%$ Faradaic yield) when oxidized electrochemically at modest bias voltages. Hence, in order to demonstrate the feasibility of the second main advantage of this approach (generation of hydrogen by reoxidation of the ECPB in a separate device to the solar-harvesting array), we reoxidized the $\left[\mathrm{PMo}_{12} \mathrm{O}_{40}\right]^{5-}$ produced during water oxidation electrochemically in a cell containing the reduced $\left[\mathrm{PMo}_{12} \mathrm{O}_{40}\right]^{5-}$ buffer in one compartment and $1 \mathrm{M}$ methanesulfonic acid in the other at $+0.75 \mathrm{~V}$ vs $\mathrm{Ag} / \mathrm{AgCl}$ (see section SI-6 in the SI). Complete reoxidation was gauged by achieving a low steady-state background current and by return of the ECPB to its original yellow color. Comparison of the charge passed during reoxidation and the amount of hydrogen evolved revealed full Faradaic efficiency for decoupled $\mathrm{H}_{2}$ production. The charge passed during reoxidation was also identical to the charge passed during initial reduction of the ECPB during the photodriven water oxidation step. Hence this ECPB makes a good mediator for potential solar-to-hydrogen applications, greatly reducing gas crossover and allowing $\mathrm{O}_{2}$ and $\mathrm{H}_{2}$ to be generated at different rates and at different times on account of these two processes being electrochemically decoupled. A rough estimation of the overall efficiency of this system (energy in vs energy out) gives a figure of between 1 and $2 \%$ (see SI).

In summary, we have demonstrated that a combined solarelectrochemical system that uses an ECPB to decouple the half reactions of water splitting is feasible. The potential benefits of this approach include reduced gas mixing at low current densities (due to decoupling of the half-reactions), the potential for hydrogen to be generated more rapidly than the oxygen (i.e., at a rate which is not limited by the solar flux), and the ability to generate the hydrogen at a time and place distinct from the large surface-area solar-harvesting array (for ease of collection and pressurization, and for the most effective use of the electrochemical cell and its components). A further benefit may include the ability to use membranes other than Nafion in the large area array, as the gas permeability of the membrane is less of an issue if oxygen evolution and hydrogen evolution are decoupled (the separator need only prevent the ECPB from accessing the anode compartment). Cheaper separators are highly desirable if large area arrays are to be made affordable, and one such cheap candidate material for this role is cellulose, which we have already demonstrated performs similarly to Nafion in decoupled water splitting mediated by $\left[\mathrm{PMo}_{12} \mathrm{O}_{40}\right]^{3-}$. ${ }^{2 a}$ Certain key challenges still remain in this approach (especially regarding increasing the current densities for water oxidation), and efforts toward improving this system are currently underway in our laboratories.

\section{ASSOCIATED CONTENT}

\section{S Supporting Information}

The Supporting Information is available free of charge on the ACS Publications website at DOI: 10.1021/jacs.6b03187.

Experimental details and data (PDF)

\section{AUTHOR INFORMATION}

\section{Corresponding Authors}

*mark.symes@glasgow.ac.uk

*lee.cronin@glasgow.ac.uk 


\section{Notes}

The authors declare no competing financial interest.

\section{ACKNOWLEDGMENTS}

This work was supported by the EPSRC (grants nos. EP/ $\mathrm{J} 015156 / 1 ; \mathrm{EP} / \mathrm{L} 023652 / 1 ; \mathrm{EP} / \mathrm{I033459/1}$; EP/J015156/1; $\mathrm{EP} / \mathrm{K} 023004 / 1 ; \mathrm{EP} / \mathrm{L} 023652 / 1)$, and EC grant 318671 (MICREAGENTS). L.C. thanks the Royal Society/Wolfson Foundation for a Merit Award and the ERC for an Advanced Grant (ERC-ADG, 670467 SMART-POM). M.D.S. acknowledges the University of Glasgow for a Kelvin Smith Research Fellowship. P.J.K. was supported in part by National Research Council, Poland under Maestro Project. The datasets underpinning this work can be obtained by contacting L.C.

\section{REFERENCES}

(1) (a) Cai, Y.; Judd, K. L.; Lenton, T. M.; Lontzek, T. S.; Narita, D. Proc. Natl. Acad. Sci. U. S. A. 2015, 112, 4606. (b) Rogelj, J.; McCollum, D. L.; Reisinger, A.; Meinshausen, M.; Riahi, K. Nature 2013, 493, 79. (c) Schaeffer, M.; Kram, T.; Meinshausen, M.; van Vuuren, D. P.; Hare, W. L. Proc. Natl. Acad. Sci. U. S. A. 2008, 105, 20621.

(2) (a) Lewis, N. S.; Nocera, D. G. Proc. Natl. Acad. Sci. U. S. A. 2006, 103, 15729. (b) Blankenship, R. E.; Tiede, D. M.; Barber, J.; Brudvig, G. W.; Fleming, G.; Ghirardi, M.; Gunner, M. R.; Junge, W.; Kramer, D. M.; Melis, A.; Moore, T. A.; Moser, C. C.; Nocera, D. G.; Nozik, A. J.; Ort, D. R.; Parson, W. W.; Prince, R. C.; Sayre, R. T. Science 2011, 332, 805.

(3) (a) Cook, T. R.; Dogutan, D. K.; Reece, S. Y.; Surendranath, Y.; Teets, T. S.; Nocera, D. G. Chem. Rev. 2010, 110, 6474. (b) Armaroli, N.; Balzani, V. Chem. - Eur. J. 2016, 22, 32.

(4) See, for example: (a) Symes, M. D.; Cronin, L. In Materials for a Sustainable Future; Letcher, T. M., Scott, J. L., Eds.; RSC Publishing: Cambridge, 2012; pp 592-614. (b) Joya, K. S.; de Groot, H. J. M. ChemSusChem 2014, 7, 73. (c) Joya, K. S.; Joya, Y. F.; Ocakoglu, K.; van de Krol, R. Angew. Chem., Int. Ed. 2013, 52, 10426. (d) Tachibana, Y.; Vayssieres, L.; Durrant, J. R. Nat. Photonics 2012, 6, 511. (e) Concepcion, J. J.; House, R. L.; Papanikolas, J. M.; Meyer, T. J. Proc. Natl. Acad. Sci. U. S. A. 2012, 109, 15560. (f) Rocheleau, R. E.; Miller, E. L.; Misra, A. Energy Fuels 1998, 12, 3. (g) Yamada, Y.; Matsuki, N.; Ohmori, T.; Mametsuka, H.; Kondo, M.; Matsuda, A.; Suzuki, E. Int. J. Hydrogen Energy 2003, 28, 1167. (h) Reece, S. Y.; Hamel, J. A.; Sung, K.; Jarvi, T. D.; Esswein, A. J.; Pijpers, J. J. H.; Nocera, D. G. Science 2011, 334, 645. (i) Khaselev, O.; Turner, J. A. Science 1998, 280, 425. (j) Licht, S.; Wang, B.; Mukerji, S.; Soga, T.; Umeno, M.; Tributsch, H. J. Phys. Chem. B 2000, 104, 8920. (k) Abdi, F. F.; Han, L.; Smets, A. H. M.; Zeman, M.; Dam, B.; van de Krol, R. Nat. Commun. 2013, 4, 2195. (1) Brillet, J.; Yum, J.-H.; Cornuz, M.; Hisatomi, T.; Solarska, R.; Augustynski, J.; Grätzel, M.; Sivula, K. Nat. Photonics 2012, 6, 824. (m) Chen, Y.; Sun, K.; Audesirk, H.; Xiang, C.; Lewis, N. S. Energy Environ. Sci. 2015, 8, 1736. (n) Sathre, R.; Scown, C. D.; Morrow, W. R.; Stevens, J. C.; Sharp, I. D.; Ager, J. W.; Walczak, K.; Houle, F. A.; Greenblatt, J. B. Energy Environ. Sci. 2014, 7, 3264.

(o) Roger, I.; Symes, M. D. J. Mater. Chem. A 2016, 4, 6724.

(5) McCrory, C. C. L.; Jung, S.; Ferrer, I. M.; Chatman, S. M.; Peters, J. C.; Jaramillo, T. F. J. Am. Chem. Soc. 2015, 137, 4347.

(6) (a) Jin, J.; Walczak, K.; Singh, M. R.; Karp, C.; Lewis, N. S.; Xiang, C. Energy Environ. Sci. 2014, 7, 3371. (b) Barbir, F. Sol. Energy 2005, 78, 661. (c) Schalenbach, M.; Carmo, M.; Fritz, D. L.; Mergel, J.; Stolten, D. Int. J. Hydrogen Energy 2013, 38, 14921. (d) Chandesris, M.; Médeau, V.; Guillet, N.; Chelghoum, S.; Thoby, D.; Fouda-Onana, F. Int. J. Hydrogen Energy 2015, 40, 1353. (e) Berger, A.; Segalman, R. A.; Newman, J. Energy Environ. Sci. 2014, 7, 1468.

(7) Ivy, J. Summary of Electrocatalytic Hydrogen Production, Milestone Completion Report; National Renewable Energy Laboratory: Golden, CO, 2004.
(8) (a) Symes, M. D.; Cronin, L. Nat. Chem. 2013, 5, 403. (b) Rausch, B.; Symes, M. D.; Cronin, L. J. Am. Chem. Soc. 2013, 135, 13656. (c) Rausch, B.; Symes, M. D.; Chisholm, G.; Cronin, L. Science 2014, 345, 1326.

(9) (a) Darwent, J. R.; Mills, A. J. Chem. Soc., Faraday Trans. 2 1982, 78, 359. (b) Grätzel, M. Nature 2001, 414, 338. (c) Wang, F.; Di Valentin, C.; Pacchioni, G. J. Phys. Chem. C 2012, 116, 8901. (d) Coridan, R. H.; Shaner, M.; Wiggenhorn, C.; Brunschwig, B. S.; Lewis, N. S. J. Phys. Chem. C 2013, 117, 6949. (e) Huang, Z.-F.; Song, J.; Pan, L.; Zhang, X.; Wang, L.; Zou, J.-J. Adv. Mater. 2015, 27, 5309.

(10) (a) Santato, C.; Ulmann, M.; Augustynski, J. J. Phys. Chem. B 2001, 105, 936. (b) Santato, C.; Odziemkowski, M.; Ulmann, M.; Augustynski, J. J. Am. Chem. Soc. 2001, 123, 10639. (c) Solarska, R; Bienkowski, K.; Zoladek, S.; Majcher, A.; Stefaniuk, T.; Kulesza, P. J.; Augustynski, J. Angew. Chem., Int. Ed. 2014, 53, 14196.

(11) See, for example: (a) Hodes, G.; Cahen, D.; Manassen, J. Nature 1976, 260, 312. (b) Miller, E. L.; Paluselli, D.; Marsen, B.; Rocheleau, R. E. Sol. Energy Mater. Sol. Cells 2005, 88, 131. (c) Miller, E. L.; Marsen, B.; Cole, B.; Lum, M. Electrochem. Solid-State Lett. 2006, 9, G248. (d) Hill, J. C.; Choi, K.-S. J. Phys. Chem. C 2012, 116, 7612. (e) de Respinis, M.; De Temmerman, G.; Tanyeli, I.; van de Sanden, M. C. M.; Doerner, R. P.; Baldwin, M. J.; van de Krol, R. ACS Appl. Mater. Interfaces 2013, 5, 7621. (f) Spurgeon, J. M.; Velazquez, J. M.; McDowell, M. T. Phys. Chem. Chem. Phys. 2014, 16, 3623. (g) Walczak, K.; Chen, Y.; Karp, C.; Beeman, J. W.; Shaner, M.; Spurgeon, J.; Sharp, I. D.; Amashukeli, X.; West, W.; Jin, J.; Lewis, N. S.; Xiang, C. ChemSusChem 2015, 8, 544. (h) Bignozzi, C. A.; Caramori, S.; Cristino, V.; Argazzi, R.; Meda, L.; Tacca, A. Chem. Soc. Rev. 2013, 42, 2228. (i) Wang, N.; Wang, D.; Li, M.; Shi, J.; Li, C. Nanoscale 2014, 6, 2061. (j) Miseki, Y.; Kusama, H.; Sugihara, H.; Sayama, K. J. Phys. Chem. Lett. 2010, 1, 1196. 